American Journal of Animal and Veterinary Sciences 6 (4): 187-192, 2011

ISSN 1557-4555

(C) 2011 E. Issabeagloo et al., This open access article is distributed under a Creative Commons Attribution

(CC-BY) 3.0 license

\title{
Hepatoprotective Effect of Taurine Against Oxidative Stress Due to Methotrexate in Rat
}

\author{
${ }^{1}$ Issabeagloo, E., ${ }^{1}$ M. Taghizadiyeh and ${ }^{2} \mathrm{P}$. Kermanizadeh \\ ${ }^{1}$ Department of Pharmacology, \\ ${ }^{2}$ Department of Basic Sciences, \\ Medical Sciences Faculty, Tabriz Branch, Islamic Azad University, Tabriz, Iran
}

\begin{abstract}
Problem statement: Taurine, 2-aminoethanesulphonic acid is an essential amino acid. It is present at high concentrations in many tissues. It plays important roles in numerous physiological functions including conjugation with bile acids, modulation of calcium levels and maintenance of osmolarity, antioxidation and stabilization of membranes. Methotrexate (MTX), as the most disease modifying anti-rheumatic drug used for Rheumatoid Arthritis (RA), has been available for clinical use since 1951. The main scope of this study was to assessment of probable Hepatoprotective effect of taurine as it antioxidant action against oxidative stress due to methotrexate in rats. Approach: Eighty male Wistar rats, weighing $200 \pm 20$ gr, were obtained from the animal breeding center of Islamic Azad University. The rats were divided into 4 equal groups of 20 animals including: 1-normal control, 2normal rats treated with taurine, 3- taurine + methotrexate and 4-methotrexate. Results: Methotrexateinduced hepatotoxicity as reflected by elevated serum ALT, AST and GGT levels $(\mathrm{p}<0.001)$ and reduced serum total protein level $(\mathrm{p}<0.001)$. Conclusion: Taurine has a protective action against hepatotoxins and suggest that taurine may find clinical application against a variety of toxins where cellular damage is a consequence of reactive oxygen species.
\end{abstract}

Key words: Methotrexate, taurine, hepatoprotective, oxidative stress, rats

\section{INTRODUCTION}

Taurine, 2-aminoethanesulphonic acid is an essential amino acid. It is present at high concentrations in many tissues. It plays important roles in numerous physiological functions including conjugation with bile acids, modulation of calcium levels and maintenance of osmolarity, antioxidation and stabilization of membranes (Huxtable, 1992; Schrader et al., 2009). It was reported to have beneficial effects in various physiological and pathological conditions (Ahn et al., 2001; Chiba et al., 2002; Ozturk et al., 2003) by mainly diminishing production of Reactive Oxygen Species (ROS). It also can prevent DNA damage at physiological concentrations (Heibashy et al., 2008; Messina and Dawson, 2000). Taurine has also hepatoprotective effects such as inhibition of extracellular matrix accumulation in experimental liver fibrosis (Balkan et al., 2001; Chen et al., 1999) and improvement of liver function tests in fatty liver disease of children (Obinata et al., 1996). Hepatoprotective feature of taurine is attributed to its inhibitory activity on generation of ROS, which are known to play an important role in hepatic injury both in vitro and in vivo (Pietrangelo, 1996; Baroni et al., 1998). Moreover, several authors reported beneficial effects of taurine on histopathology and oxidative stress parameters in a rat model of CCl4-induced liver fibrosis (RefikMas et al., 2004; Tasci et al., 2007) where remarkable Histopathological improvement in taurine treated animals subjected to hepatotoxin was observed and this was associated with oxidative stress reduction and hepatocellular apoptosis. Taurine in addition to it's antioxidant effect has other performances such as it Implicated in Bromocriptine Induced Schizophrenia (Abdulrahim, 2010).

Methotrexate (MTX), as the most disease modifying anti-rheumatic drug used for Rheumatoid Arthritis (RA), has been available for clinical use since 1951 (Wilkens and Watson, 1982; Ralandison et al., 2012). Its widespread availability along with the high prevalence of RA which requires long-term therapy has attracted physicians' attention to the adverse reactions of MTX.

Antagonism with folic acid and The increases in aminotransferases (transaminitis) are a potential major adverse reaction seen with long-term use of MTX. Many

Corresponding Author: Issabeagloo, E., Department of Pharmacology, Medical Sciences Faculty, Tabriz Branch, Islamic Azad University, Tabriz, Iran Tel: +989144079927 
risk factors such as age, duration of exposure to MTX and its cumulative dose, history of Non Alcoholic Steatohepatitis (NASH), diabetes and obesity, hepatitis B or $\mathrm{C}$ virus infection, alcohol consumption and hepatotoxic drugs can increase the hepatotoxic effect of MTX (Lorenz and Knudtson, 2007; Diouf et al., 2001; Visser et al., 2009; Jones and Patel, 2000; Kremer et al., 1995; Langman et al., 2001; Leonard et al., 1987; Malatjalian et al., 1996; Reynold and Lee, 1986; Salliot, C. and Heijde D.V.D., 2009; Walker et al., 1993).

\section{MATERIALS AND METHODS}

Experimental plan: This experimental study was carried out in Islamic Azad University Research Center. All procedures were conducted under supervision of Animal Rights Monitoring Committee of Islamic Azad University Research Center.

Chemicals: All chemicals used in this study were of analytical grade and obtained from Nanjing Jiancheng Bioengineering Institute, Nanjing, China and Ziest Chemi Co., Iran.

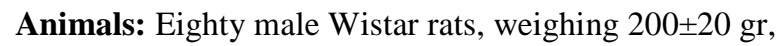
were obtained from the animal breeding center of Islamic Azad University. The rats were divided into 4 equal groups of 20 animals including: (1) Normal control, (2) Normal rats treated with taurine, (3) Taurine + methotrexate and (4) Methotrexate. Management and husbandry conditions were identical in all groups with $12 / 12 \mathrm{~h} \mathrm{light/dark}$ cycle at $21 \pm 2^{\circ} \mathrm{C}$. Food and water were provided ad libitum.

Biochemical factors evaluation: At the end of the experiment, blood samples were collected from the retro-orbital plexus and the sera prepared through centrifuging at $2500 \times \mathrm{g}$ for $15 \mathrm{~min}$ at $30^{\circ} \mathrm{C}$ After $12 \mathrm{~h}$ fasting, blood glucose and serum biomarkers of liver function including ALT, AST (humoller et al, 1957), LDH (Martinek, 1972), albumin, TP (Lowry et al., 1951) and total bilirubin (Malloy and Evelyn, 1936) were measured using commercially available kits.

Measurement of antioxidant activity: All experimental rats were euthanized by cervical dislocation. The rat's Liver were removed immediately and washed in normal saline and homogenate $10 \%$ prepared in $1.15 \% \mathrm{w} / \mathrm{v}$ of potassium chloride. The homogenate was centrifuged in $7000 \times \mathrm{g}$ for $10 \mathrm{~min}$ at $4^{\circ \mathrm{C}}$ and supernatant were used for measurement of Oxidative stress by determination of Malondialdehyde (MDA) as well as Antioxidant Enzymes (AOE) such as Superoxide Dismutase (SOD), catalase (CAT), glutathione peroxidase (GSH-PX) and glutathione reductase. MDA, SOD, CAT and GSH-PX, GR were measured by using commercially available kits according to the manufacturer's protocol (Nanjing Jiancheng Bioengineering Institute, Nanjing, China). Liver homogenate MDA levels were expressed as nmol MDA per mg protein and antioxidant activity was expressed as arbitrary units per mg protein.

Degree of lipid peroxidation in kidney tissue homogenates was determined in terms of thiobarbituric acid reactive substances (TBARSs) formation by following the protocol of Esterbauer and Cheesman (1990). SOD activity was measured by Nishikimi et al. (1972) method and was modified by Kakkar et al. (1984) method. Each unit of SOD activity was determined as required enzyme concentration for prohibition of creation color at 1 minute, under study conditions. CAT activity was measured by Greenwald (1985) method and was based on hydrogen peroxide breakdown. GPX activity was measured by Rotruck et al. (1973) method and was expressed as micromole of GSSG/minute/milligram of protein, based on blew reaction:

\section{$2 \mathrm{H}_{2} \mathrm{O}+\mathrm{GSSG} \rightarrow \mathrm{H}_{2} \mathrm{O}_{2}+2 \mathrm{GSH}$}

GR activity was measured by Mohandas et al. (1984) method, based on blew reaction:

\section{$\mathrm{NADPH}+\mathrm{H}^{+}+\mathrm{GSSG} \rightarrow \mathrm{NADP}^{+}+2 \mathrm{GSH}$}

Statistical analysis: The Statistical Package for Social Sciences (SPSS Inc., Chicago, IL, USA), version 13.0, was used for statistical analysis. All data are presented as mean \pm SEM. Before statistical analysis, all variables were checked for normality and homogeneity of variance by using the Kolmogorov-Smirnoff and Levene tests, respectively. The data obtained were tested by ANOVA followed by Tukey's post-hoc multiple comparison test. $\mathrm{p}<0.05$ was considered statistically significant.

\section{RESULTS}

Effect of taurine on MTX-induced hepatotoxicity: As shown in (Table 1), MTX-induced hepatotoxicity mirrored by increscent in serum ALT, AST and GGT levels $(\mathrm{p}<0.001)$ and diminished serum total protein level $(\mathrm{p}<0.001)$. After treatment by taurine, no markedly changes were obtained. On the other hand, rats treated with taurine and MTX had markedly increased serum total protein level $(\mathrm{p}<0.01)$ and lower serum ALT, AST and GGT levels compared with MTX group $(\mathrm{p}<0.001)$. 


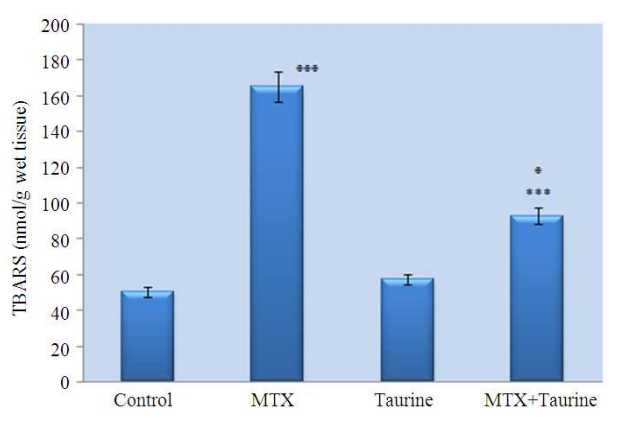

Fig. 1: Effect of taurine supplementation (1\% in the drinking water) for 3 weeks on hepatic TBARS concentration in hepatotoxicity due to MTX in rat. Values are expressed as mean \pm S.E.M., $\mathrm{n}=20 . * * * \mathrm{p}<0.001$ compared with MTX group. $p<0.05$ compared with control group

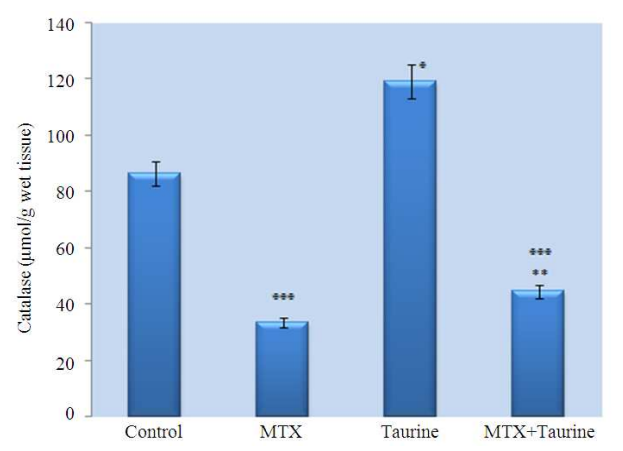

Fig. 2: Effect of taurine supplementation (1\% in the drinking water) for 3 weeks on hepatic Catalase concentration in hepatotoxicity due to MTX in rat. Values are expressed as mean \pm S.E.M., $\mathrm{n}=20 . * * \mathrm{p}<0.01$ compared with MTX group. $p<0.001$, $p<0.05$ compared with control group

Effect of taurine on MTX -induced oxidative stress: Effect of taurine on lipid peroxidation: As cited in Fig. 1, TBARS concentration was increased in MTX treated rats $\left(164.66 \pm 9.21 \mathrm{nmol} \mathrm{g}^{-1}\right.$ wet tissue, $\left.\mathrm{p}<0.001\right)$ as compared to normal control rats $(49.98 \pm 7.13 \mathrm{nmol}$ $\mathrm{g}^{-1}$ wet tissue). Treatment with taurine prohibited MTX -induced lipid peroxidation and leads to significant decline in TBARS level $(92.51 \pm 6.44 \mathrm{nmol} / \mathrm{g}$ wet tissue, $\mathrm{p}<0.001)$ as compared to MTX group alone.

Effect of taurine on catalase activity: As figured in Fig. 2, the activity of catalase was markedly decreased in MTX group $\left(33.67 \pm 3.19 \_\mathrm{mol} / \mathrm{min} / \mathrm{mg}\right.$ wet tissue, $\mathrm{p}<0.001)$ as compared to normal control group $\left(86.39 \pm 2.12 \_\mathrm{mol} / \mathrm{min} / \mathrm{mg}\right.$ wet tissue $)$.
Table 1: Effect of taurine supplementation (1\% in the drinking water) for 3 weeks on hepatotoxicity due to MTX in rat

\begin{tabular}{|c|c|c|c|c|}
\hline & Control & $\begin{array}{l}\text { MTX } \\
\left(20 \mathrm{~m} \mathrm{~kg}^{-1}\right)\end{array}$ & $\begin{array}{l}\text { Taurine ( } 1 \% \text { in } \\
\text { drinking water) }\end{array}$ & MTX + taurine \\
\hline$\overline{\mathrm{ALT}}$ & $17.04 \pm 1.88$ & $49.87 \pm 6.29^{\text {wats }}$ & $17.89 \pm 0.44$ & $35.5 \pm 1.71^{* *}$ \\
\hline AST & $44.04 \pm 2.13$ & $157.5 \pm 6.18^{m}$ & $46.21 \pm 1.88$ & $72.08 \pm 2.81^{* * * * *}$ \\
\hline GGT & $3.08 \pm 0.09$ & $5.71 \pm 0.26^{6}$ & $3.04 \pm 0.13$ & $4.16 \pm 0.23^{* * * *}$ \\
\hline Total protein & $5.18 \pm 0.22$ & $6.34 \pm 0.19^{m * 4}$ & $5.25 \pm 0.39$ & $7.25 \pm 0.67^{* * * *}$ \\
\hline
\end{tabular}

Table 2: Correlation coefficient (r) between biochemical parameters of hepatotoxicity and oxidative stress

\begin{tabular}{lllll}
\hline & CAT & GSH-Px & GSH & TBARS \\
\hline ALT & $-0.798^{*}$ & $-0.811^{*}$ & $-0.645^{*}$ & $0.826^{*}$ \\
AST & $-0.686^{*}$ & $-0.796^{*}$ & $-0.733^{*}$ & $0.785^{*}$ \\
GGT & $-0.921^{*}$ & $-0.752^{*}$ & $-0.841^{*}$ & $0.766^{*}$ \\
Total protein & $0.652^{*}$ & $0.688^{*}$ & $0.556^{*}$ & $-0.719^{*}$ \\
MDA & $-0.721^{*}$ & $-0.5978^{*}$ & $-0.71465^{*}$ & --- \\
\hline *:p<0.0001 & & & &
\end{tabular}

But, Taurine exclusively increased catalase activity (119.27 $\pm 8.92 \_\mathrm{mol} / \mathrm{min} / \mathrm{mg}$ wet tissue, $\left.\mathrm{p}<0.05\right)$. Taurine supplementation reduced MTX -induced catalase inhibition and increased catalase activity high than $\left(44.61 \pm 1.88 \_\mathrm{mol} / \mathrm{min} / \mathrm{mg}\right.$ wet tissue, $\left.\mathrm{p}<0.01\right)$ as compared to MTX group only.

Effect of taurine on GSH-Px activity: As demonstrated in Fig. 3, GSH-Px activity was reduced in those rats which treated by MTX $\left(4.19 \pm 0.22 \_\mathrm{mol} / \mathrm{min} / \mathrm{g}\right.$ wet tissue, $\mathrm{p}<0.001)$ as compared to normal control rats $\left(5.11 \pm 0.78 \_\mathrm{mol} / \mathrm{min} / \mathrm{g}\right.$ wet tissue $)$. Taurine alone elevated GSH-Px activity $\left(8.18 \pm 0.23 \_\mathrm{mol} / \mathrm{min} / \mathrm{g}\right.$ wet tissue, $\mathrm{p}<0.01)$. Treatment with taurine yields to significant increscent in GSH-Px activity $\left(4.61 \pm 0.119 \_\mathrm{mol} / \mathrm{min} / \mathrm{g}\right.$ wet tissue, $\left.\mathrm{p}<0.001\right)$ as compared to MTX group alone.

Effect of taurine on GSH concentration: As showed in Fig. 4, MTX produced a decrement of hepatic GSH content $\left(0.49 \pm 0.016 \_\mathrm{mol} \mathrm{g}^{-1}\right.$ wet tissue, $\left.\mathrm{p}<0.01\right)$ as compared to normal control group $\left(1.89 \pm 0.341 \_\mathrm{mol} \mathrm{g}^{-1}\right.$ wet tissue). Taurine alone induced a considerably increase in its level $\left(4.249 \pm 0.116 \_\mathrm{mol} / \mathrm{g}\right.$ wet tissue, $\mathrm{p}<0.001)$ compared with the control group. Treatment with taurine depredated MTX induced GSH depletion and increased GSH concentration $\left(1.072 \pm 0.056 \_\mathrm{mol} / \mathrm{g}\right.$ wet tissue, $\mathrm{p}<0.05$ ) as compared to MTX group alone.

Correlation analysis: Based on obtained data, TBARS has direct correlation with biochemical parameters related to hepatic injury. This indicates that lipid peroxidation has important role in MTX induced hepatic injury. 


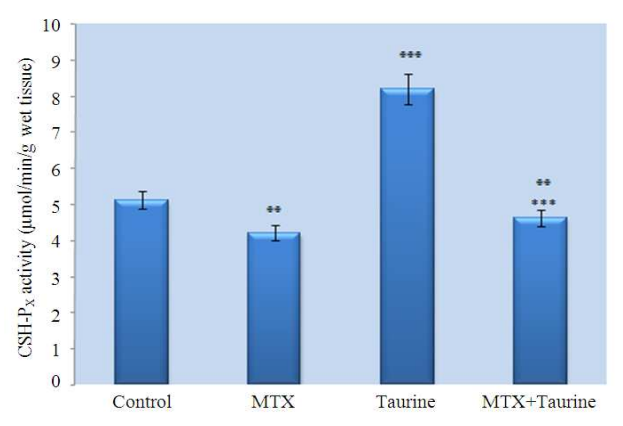

Fig. 3: Effect of taurine supplementation (1\% in the drinking water) for 3 weeks on hepatic GSHPx activity in hepatotoxicity due to MTX in rat. Values are expressed as mean \pm S.E.M., $n$ $=20 . * * * p<0.001$ compared with MTX group. w $p<0.001$, $<0.01$ compared with control group

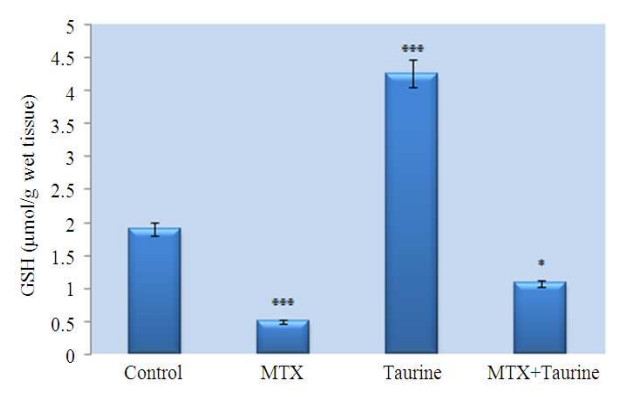

Fig. 4: Effect of taurine supplementation (1\% in the drinking water) for 3 weeks on hepatic GSH concentration in hepatotoxicity due to MTX in rat. Values are expressed as mean \pm S.E.M., $\mathrm{n}=20 . * \mathrm{p}<0.05$ compared with MTX group. $p<0.001$, $p<0.01$ compared with control group

Contrary, TBARS has reverse correlation with internal antioxidants. Also, hepatotoxicity indications were inversely correlated with internal antioxidant enzymes. Finally can be conclude that internal antioxidants have protective effect against ROS (Table 2).

\section{DISCUSSION}

The protective capacity of taurine was attributed to free radicals scavenging. Subjects treated with placebo showed a significant increase in the number of severely damage mitochondria after reperfusion, whereas the number of damaged and necrotic myocytes also increased significantly in these subjects after infusion. No such damage to mitochondria or myocytes was observed in the taurine treated subjects (Lee et al., 1992). The use of supplemental taurine as a physiological protective against lipid peroxidation was advocated by Gordon et al (1986) who demonstrated the protection of hamaster bronchioles from acute $\mathrm{NO}_{2}$ induced alterations. The authors outlined the mechanism through which acute ROS tissue damage is believed to act. $\mathrm{NO}_{2}$ and its highly ROS interact directly with plasma membrane of cell products, possibly via lipid peroxidation triggering a series of events that include the release of chemotactic factors and acute phase reactions responsible for the influx of neutrophils. Activation of neutrophils results in production of superoxide, free radicals and hydrogen peroxide $\left(\mathrm{H}_{2} \mathrm{O}_{2}\right)$, which cause further epithelial damage. Activated neutrophils also release proteolytic enzymes that have the capacity to alter alveolar interstitial components. It was proposed by Gordon et al. (1986) and Cardin et al. (1999) that the protective activity of taurine may reside in its ability to become chlorinated in the presence of HOCL, thereby preventing the direct attack of this oxidant on cell membranes (Rock et al., 1996). Lee et al. (1992) postulated that the protective action of taurine on oxidant-induced damages of tissue components including degradation of hyaluronic acid may be attributed to both its scavenging action on hypochloriate $(\mathrm{HOCl})$ and chloramine and the complex formation of taurine with $\mathrm{HOCl}$ or $\mathrm{NH} 2 \mathrm{Cl}$ without scavenging action on oxygen free radicals.

El-Nahrawy et al., 2011 showed that the best ameliorating effect occurred in all hepatic markers in rats group which treated with both antioxidants (taruine and curcumin) dependent on time of administration (Walaa et al., 2011).

Hagar (2004), demonstrated that Taurine administration (1\% in the drinking water) for 3 days before and concurrently during CsA injections improved liver functions, as indicated by decline of serum transaminases and GGT levels and elevation of serum total protein. Moreover, taurine significantly reduced hepatic TBARS and increased GSH content and catalase and GSH-Px activities in the hepatic tissue (Hagar, 2004).

Jagadeesan and Pillai (2007), reported that liver tissue was completely damaged, after mercury treatment. In another group of animals, taurine $(5 \mathrm{mg}$ $\mathrm{kg}^{-1}$ body wt.) was administrated for another 15 days. Taurine administration was observed to improve the liver function in mercury intoxicated animal as indicated by the decline in increased levels of AST, ALT and ALP in serum and LPO content in liver tissue. The decreased level of antioxidant system (GSH, GPx, CAT and SOD) has been promoted (Jagadeesan and Pillai, 2007). 


\section{CONCLUSION}

These results indicate that taurine has a protective action against hepatotoxins and suggest that taurine may find clinical application against a variety of toxins where cellular damage is a consequence of reactive oxygen species.

\section{REFERENCES}

Ahn B.O., K.H. Kim, G. Lee, H.S. Lee and C.D. Kim et al., 2001. Effects of taurine on cerulein-induced acute pancreatitis in the rat. Pharmacology, 63: 1-7. DOI: $10.1159 / 000056106$

Balkan, J., S. Dogru-Abbasoglu, O. Kanbagli, U. Cevikbas and G. Aykac-Toker et al., 2001. Taurine has a protective effect against thioacetamideinduced liver cirrhosis by decreasing oxidative stress. Hum. Exp. Toxicol., 20: 251-254. DOI: 10.1191/096032701678227758

Baroni, S.G., L. D’Ambrosio, G. Ferretti, A. Casini and D.A. Sario et al., 1998. Fibrogenic effect of oxidative stress on rat hepatic stellate cells. Hepatology, 27: 720-726. DOI: 10.1002/hep.510270313

Cardin, V., C. Pena-Segura and H. Pasants-Morales, 1999. Activation and inactivation of taurine efflux in hyposmotic and isosmotic swelling in cortical astrocytes: Role of ionic strength and cell volume decrease. J. Neurosci. Res., 56: 659-667. PMID: 10374821

Chen, Y., S. Li and X. Zhang, 1999. Taurine inhibits deposition of extracellular matrix in experimental liver fibrosis in rats. Zhonghua Gan Zang Bing Za Zhi.., 7: 165-167. PMID: 10572688

Chiba, Y., K. Ando and T. Fujita, 2002. The protective effects of taurine against renal damage by salt loading in Dahl salt-sensitive rats. J. Hypertens, 20: 2269-2274. PMID: 12409966

Diouf, M.L., S. Diallo, M. Mbengue and T. MoreiraDiop, 2001. Methotrexate, liver and rheumatoid arthritis in tropical areas. Sante, J., 11: 195-200. PMID: 11641084

Esterbauer, H. and K.H. Cheesman, 1990. Determination of aldehydic lipid peroxidation products: Malonaldehyde and 4-hydroxynonenal. Methods Enzymol, 186: 407-421. PMID: 2233308

Gordon, R.E., A.A. Shaked and D.F. Solana, 1986. Taurine protects hamster bronchioles from acute NO2-induced alterations. A histologic, ultrastructural, and freeze-fracture study. Am. J. Pathol., 125: 585-600.
Greenwald, R.A., 1985. CRC Handbook of Methods for Oxygen Radical Research. 1st Edn., CRC Press, Boca Raton, Florida, ISBN: 0849329361, pp: 447.

Hagar, H.H., 2004. The protective effect of taurine against cyclosporine A-induced oxidative stress and hepatotoxicity in rats. Toxicol. Lett., 151: 335-343. PMID: 15183458

Heibashy, M.I. and M.N. Sharoud, 2008. Attenuation of the disruptive effects induced by $\gamma$-irradiation in rats using ozonated water and/or taurine. Isotope Rad. Res., 40: 1527-1541.

Humoller F.L., J.M. Holthaus and J.R. Walsh, 1957. Improved method for the colorimetric determination of glutamic-oxalacetic transaminase activity. Clin Chem., 3: 703-710. PMID: 13489889

Huxtable, R.J., 1992. Physiological actions of taurine. Physiol. Rev., 72: 101-163. PMID: 1731369

Jagadeesan, G. and S.S. Pillai, 2007. Hepatoprotective effects of taurine against mercury induced toxicity in rats. J. Environ. Biol., 28: 753-756. PMID: 18405108

Jayyab, A.A., 2010. Taurine Implicated in Bromocriptine Induced Hallucination: GlycineGlutamic-Aspartic Implicated in Bromocriptine Induced Schizophrenia. Am J Pharm and Toxi, 5: 34-41. DOI: 10.3844/ajptsp.2010.34.41

Jones, K.W. and S.R. Patel, 2000. A family physician's guide to monitoring methotrexate. Am. Fam. Physician., 62: 1607-1614. PMID: 11037077

Kakkar, P., B. Das and P.N. Viswanathan, 1984. A modified spectrophotometric assay of superoxide dismutase. Indian J. Biochem. Biophys., 21: 130132. PMID: 6490072

Kremer, J.M., G.F. Petrillo and R.A. Hamilton, 1995. Pharmacokinetics and renal function in patients with rheumatoid arthritis receiving a standard dose of oral weekly methotrexate: association with significant decreases in creatinine clearance and renal clearance of the drug after 6 months of therapy. J. Rheumatol., 22: 38-40. PMID: 7699678

Langman, G., P.M. Hall and G. Todd, 2001. Role of non-alcoholic steatohepatitis in methotrexateinduced liver injury. J. Gastroenterol. Hepatol., 16: 1395-1401. PMID: 11851839

Lee, S.P., J.F. Nicholls and H.Z. Park, 1992. Biliary sludge as a cause of acute pancreatitis. N. Engl. J. Med., 27: 589-593. PMID: 1734248

Leonard, P.A., D.O. Cleg, C.C. Carson, G.W. Cannon and M.J. Eqqer et al., 1987. Low dose pulse methotrexate in rheumatoid arthritis: An 8-year experience with hepatotoxicity. Clin. Rheumatol., 6: 575-582. PMID: 3449308 
Lorenz, L.B. and E.J. Knudtson, 2007. Anomalies in a fetus exposed to methotrexate in the first trimester. Am. J. Pharmacol. Toxicol., 2: 146-147. DOI: 10.3844/ajptsp.2007.146.147

Lowry, O.H., N.J. Rosebrough, A.L. Farr and R.J. Randall, 1951. Protein measurement with the folin phenol reagent. J. Biol. Chem., 193: 265-275. PMID: 14907713

Malatjalian, D.A., J.B. Ross, C.N. Williams, S.J. Colwell and B.J. Eastwood, 1996. Methotrexate hepatotoxicity in psoriatics: report of 104 patients from Nova Scotia, with analysis of risks from obesity, diabetes and alcohol consumption during long term follow-up. Can. J. Gastroenterol., 10: 369-375. PMID: 9193771

Malloy, H.T. and KA Evelyn, 1937. The determination of bilirubin level with the photoelectric colorimeter. J. Biol. Chem., 119: 481-484.

Martinek, R.G., 1972. A rapid ultraviolet spectrophotometric lactic dehydrogenase assay. Clin. Chem. Acta., 40: 91-99. DOI: 10.1016/00098981(72)90254-9

Messina, S.A. and D.R. Jr. Dawson, 2000. Attenuation of oxidative damage to DNA by taurine and taurine analogs. Adv. Exp. Med. Biol., 483: 355-367. PMID: 11787620

Mohandas, J., J.J. Marshal, G.G. Duggin, J.S. Horvath and D.G. Tiller, 1984. Low activities of glutathione-related enzymes as factors in the genesis of urinary bladder cancer. Cancer Res., 44: 5086-5091. PMID: 6149017

Nishikimi, M., N.A. Rao and K. Yagi, 1972. The occurrence of superoxide anion in the reaction of reduced phenazine methosulfate and molecular oxygen. Biochem. Biophys. Res. Commun., 46: 849-854. DOI: 10.1016/S0006-291X(72)80218-3

Obinata, K., T. Maruyama, M. Hayashi, T. Watanabe and H. Nittono, 1996. Effect of taurine on the fatty liver of children with simple obesity. Adv. Exp. Med. Biol., 403: 607-613. PMID: 8915401

Ozturk, M., M.R. Mas, M. Yasar, C. Akay and H. Aydogan et al., 2003. The role of inducible nitric oxide synthase inhibitor, meropenem, and taurine in experimental acute necrotizing pancreatitis. Pancreas, 26: 357-362. PMID: 12717268

Pietrangelo, A., 1996. Metals, oxidative stress and hepatic fibrogenesis. Semin Liver. Dis., 16: 13-30. PMID: 8723320

Ralandison, S., E. Rafalimanana, H. Rakotonirainy and Rabenja R., 2012. International clinical practice guidelines and management of rheumatology in Madagascar. Bull. Soc. Pathol. Exot., DOI: 10.1007/s13149-012-0205-X
RefikMas, M., B. Comert, K. Oncu, S.A. Vural and C. Akay et al., 2004. The effect of taurine treatment on oxidative stress in experimental liver fibrosis. Hepatol. Res., 28: 207-215. PMID: 15040961

Reynold, F.S. and W.M. Lee, 1986. Hepatotoxicity after long-term methotrexate therapy. South. Med. J., 79: 536-539. PMID: 3704718

Rock, C.L., R.A. Jacob and P.E. Bowen, 1996. Update on the biological characteristics of the antioxidant micronutrients: vitamin $\mathrm{C}$, vitamin $\mathrm{E}$, and the carotenoids. J. Am. Diet. Assoc., 96: 693-702. PMID: 8675913

Rotruck, J.T., A.L. Pope, H.E. Ganther, A.B. Swanson and D.G. Hafeman et al., 1973. Selenium: Biochemical role as a component of glutathione peroxidase. Science, 179: 588-590. DOI: 10.1126/science.179.4073.588

Salliot, C. and D.V.D. Heijde, 2009. Long-term safety of methotrexate monotherapy in patients with rheumatoid arthritis: A systematic literature research. Ann Rheum Dis., 68:1100-4.

Schrader, H., B.A. Menge, O. Belyaev, W. Uhl and W.E. Schmidt et al., 2009. Amino acid malnutrition in patients with chronic pancreatitis and pancreatic carcinoma. Pancreas, 38: 416-421. PMID: 19169171

Tasci, I., M.R. Mas, S.A. Vural, S. Deveci and B. Comert et al., 2007. Pegylated interferon-alpha plus taurine in treatment of rat liver fibrosis. World. J. Gastroenterol, 13: 3237-3244. PMID: 17589904

Visser, K. and Heijde D.M.V.D., 2009. Risk and management of liver toxicity during methotrexate treatment in rheumatoid and psoriatic arthritis: a systematic review of the literature. Clin Exp Rheumatol., 27:1017-1025. PMID: 20149325

Walaa, A., M. El-Nahrawy and M.A.H. Islam, 2011. Possible Synergistic Therapeutic Role of Taurine and Curcumin on Cerulein-Induced Acute Pancreatitis in Rats. J. Am. Sci., 7: 485-495.

Walker, A.M., D. Funch, N.A. Dreyer, K.G. Tolman and J.M. Kremer et al., 1993. Determinants of serious liver disease among patients receiving lowdose methotrexate for rheumatoid arthritis. Arthritis Rheum., 36: 329-335. PMID: 8452577

Wilkens, R.F. and M.A. Watson, 1982. Methotrexate: A perspective of its use in the treatment of rheumatic diseases. J. Lab. Clin. Med., 100: 314-321. PMID: 7108346 